\title{
A Study on the Learning Style Preferences with Different Academic Backgrounds-Taking Tujia EFL Learners as Examples*
}

\author{
Feng Liu \\ Faculty of English, College of Literature and Law, Sichuan Agricultural University, Ya'an, China \\ $\mathrm{Lin} \mathrm{Hu}$ \\ Faculty of English, College of Literature and Law, Sichuan Agricultural University, Ya'an, China \\ Junjian Gan \\ Faculty of English, College of Literature and Law, Sichuan Agricultural University, Ya'an, China
}

\begin{abstract}
The present study hopes to explore the learning style preferences with different academic backgrounds of Tujia EFL learners offer some suggestions for improving effectiveness of College English teaching in Tujia-Miao regions. The study adopts a multidimensional learning-styles instrument. The specific research questions involved in this study are as follows: 1 . Do the learning styles of Tujia college students vary with literal arts and science and technology majors? (1) If they do, what are the contributing factors affecting their learning style preferences? 2. How can the distributions of learning styles affect the methods of Tujia EFL classroom teaching?The subjects of this study are 146 Tujia students from 6 different departments of Jishou University in in Tujia-Miao Autonomous Prefecture of Xiangxi. Both the quantitative and qualitative researches are applied in this study. The quantitative research indicates minority students from different academic backgrounds have various learning styles. The results of the qualitative study indicated that most of the Tujia students and their teachers know little about "learning styles" and some teachers thought the research of "Tujia EFL learners' learning styles" is useless. The significant inharmony between teachers' teaching styles and students' learning styles was also discovered.
\end{abstract}

Index Terms - Tujia EFL learners, learning style preferences, academic background

\section{PRELUDE}

The method has changed from teaching to learning in the English education for past years in Western countries has brought about the rise of learning styles research. A large number of studies have shown individual differences play an important role in second language acquisition. Learners' academic backgrounds have a direct relationship with their different learning styles (Oxford, Lavine, R.Z., \& Crookall, D, 1989). The research concerning learning styles are fruitful at home and abroad, but the research regarding minority college students as their subjects are rare, the present research will have a try in this field where Tujia Enlish learners as its subjects.

\section{LITERATURE REVIEW}

\section{A. Definitions of Terms}

Many researchers have tried to define the terms of learning styles from different perspectives based on the different rationales: 1) Gregorc (1979) defined LS as "Teachers's teaching styles and learners' learning styles are virtually their own disposal of matters". 2) Keefe (1979) assumed that LS is "The composite of characteristic cognitive, affective, and physiological factors that serve as relatively stable indicators of how learners perceive, interact with, and respond to the learning environment." 3) Schmeck (1983, cited Liufeng 2012) viewed learning style as a certain kind of method or strategy. Everybody's learning methods come from some particular strategies, which indicate his/her learning styles; 4) Scarcella (1990) defined LS as "cognitive and interactional patterns which affect the ways students perceive, remember and think; 5) the definition of Oxford (1990) is "The general approaches students use to learn a new subject or tackle a new problem or overall patterns that give general direction to learning behavior."

\section{B. Categories of Learning Styles}

Since the theory of learning styles was proposed, a large number of researchers clarify learning styles in different perspectives. Here are some of the most representative ones:

\footnotetext{
${ }^{*}$ The research is supported by the "Foundation of Sichuan Agricultural University". Grant Number : SICAU06170930
} 
1. Kolb's Classification

Kolb (1984b) described learning as a four-step process consisting of concrete experience, reflective observation, abstract conceptualization and active experimentation. (See figure 1.1)

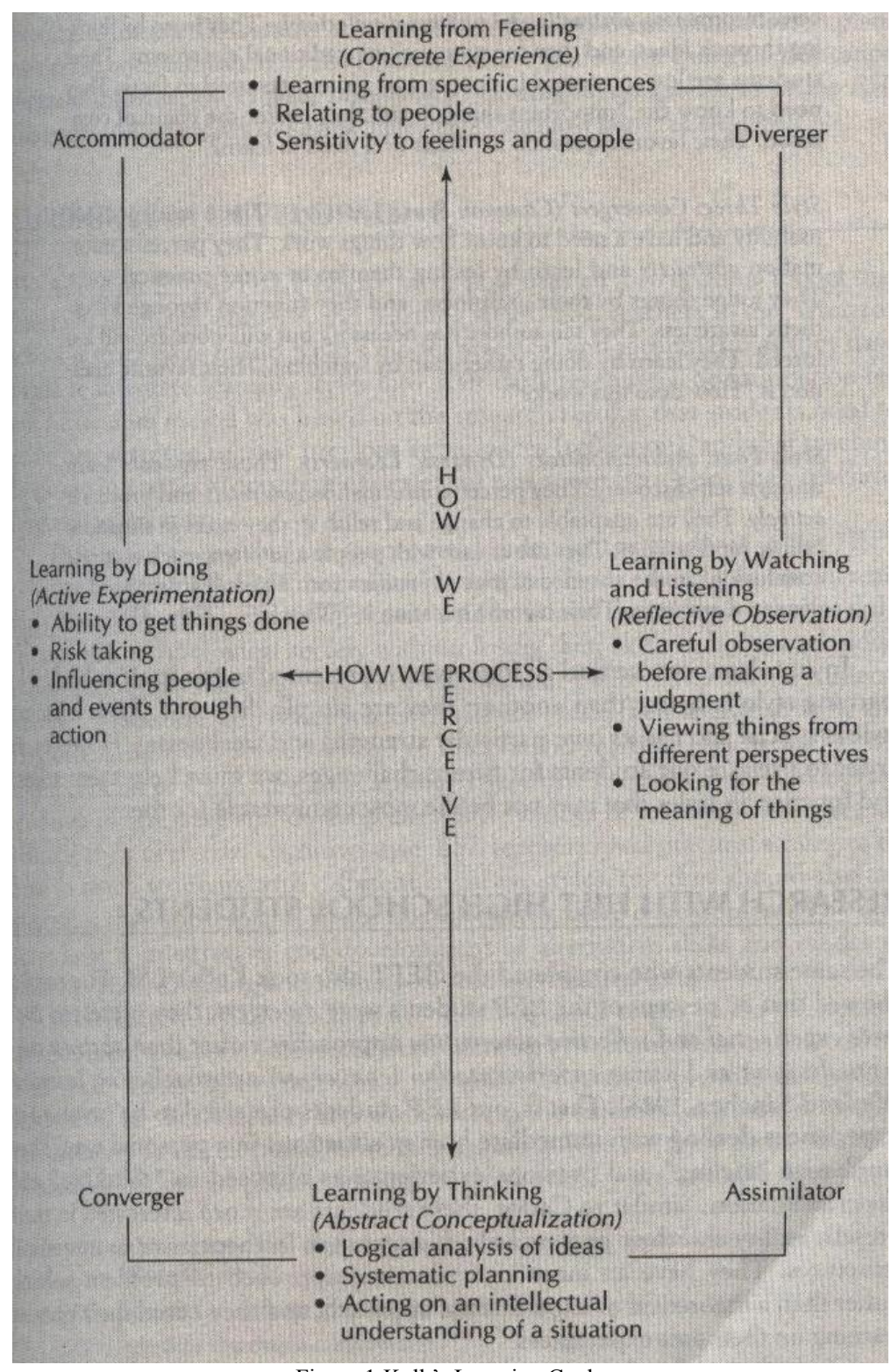

Figure 1 Kolb's Learning Cycle

Based on learners' preference to the four steps, Kolb divided learners into four types:

Diverger (Innovative Learner): Learns more effectively when she or he is able to perceive concretely and to process reflectively.

Assimilator (Analytical Learner): Learns more effectively when she or he is able to perceive abstractly and to process reflectively.

Converger (Common Sense Learner): Learns more effectively when she or he is able to perceive abstractly and to process actively.

Accommodator (Dynamic Learner): Learns more effectively when she or he is able to perceive concretely and to process actively.

Kolb's classification is particular useful because it follows the natural progression of the learning cycle:

Perception

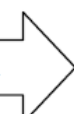

a. Students are motivated by getting involved through their concrete experiences.

b. They analyze their experiences through reflective observation. 


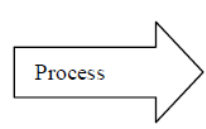

c. Students assimilate new concepts through abstract conceptualization

d. They practice their new material through active experimentation.

Finally, the students personalize information and accommodate their newly acquired knowledge to higher level experiences.

McCarthy (1980) adapted Kolb's model, she described Kolb's four learning styles as follows:

Style One: Divergers (Innovative Learners). They are divergent thinkers who believe in their own experience. They are interested in people, culture and social interaction.

Style Two: Assimilators (Analytical Learners). These learners are less interested in people and more interested in facts. They need to know the "important things" and they prefer the chain of command.

Style Three: Convergers (Common Sense Learners). They judge things by their usefulness, and they function through kinesthetic awareness. They learn by doing rather than by watching.

Style Four: Accommodators (Dynamic Learners). They are at ease with people and often reach accurate conclusions in the absence of logical justification. These learners tend to disregard authority.

\section{RESEARCH DESIGN}

\section{A. Subjects}

Subjects for the study involved 146 Tujia students from 6 departments of Jishou University. Among the 146 Tujia students, 75 are males and 71 are females. Another 4 teachers and 60 Tujia students from English Department also participate in the pre-test for instrument remedy.The details of the subjects are shown in Table1.

TABLE 1

DEPARTMENTS OF THE SUBJECTS

\begin{tabular}{llll}
\hline Department & Major & Frequency & percentage \\
\hline Chinese & Chinese language and literature & 25 & $17 \%$ \\
English & English language and literature & 28 & $19 \%$ \\
Law & Law & & \\
and & and & 28 & $19 \%$ \\
Politics & Politics & 20 & \\
Medicine & Medicine & 25 & $14 \%$ \\
Business & accountancy & 25 & $17 \%$ \\
Management & Financial & 20 & $14 \%$ \\
PE & Physical Education & 146 & $100 \%$ \\
Total & & & \\
\hline
\end{tabular}

\section{B. Instruments}

A questionnaire adapted from the researchers for the study of students' learning style preferences in Xi'an Jiaotong University (Liu \& Dai, 2003) will be used in the present study. Their learning styles questionnaire have relatively higher reliability and validity by improving for several researchers and experiments.

The interviews have 8 students and 5 teachers in it.

\section{Data Collection and Analysis}

Data collection:

First step: The pre-test was conducted in the early December by using the original questionnaire. The subjects are 60 Tujia students. They will improve some points by filling the questionnaires.

Second step: The improved one was given to Tujia students on January 10, 2010. The questionnaires will be ended in 60 minutes. 7 days are used to finish the data collection and a total of 165 questionnaires were returned to the present researcher. After a careful examination, 19 questionnaires were excluded because the results having successive similar choices.

Third step: The interviews will be carried out every week, it will lase three weeks with about 45 minutes each.

Data analysis:

An One-Way ANOVA was carried out to find out whether the Tujia students with varied majors differ significantly in their learning styles.

\section{Result AND Discussion}

Although statistical analysis did not provide as many significant differences as anticipated, the results seemed logically consistent (see Table 2). Generally speaking, reflective style is a major learning style preference and impulsive is negligible by Tujia students of almost all the majors. Table 3 further proved that reflective, individual-oriented and independent were major learning styles of Tujia students with different academic backgrounds. However, there are some 
differences in learning styles among students from different academic background.

First, the random and dependent styles were selected as negligible styles only by students from Law and Politics Department. Second, analytical style was not welcomed by all Tujia students, except those students from Chinese Department who preferred to learn analytically. Third, impulsive style was selected as a negligible style by all Tujia students, except those of English Department who regarded it as a minor learning style.

TABLE 2

LEARNING STYLES MEANS IN DIFFERENT MAJORS

\begin{tabular}{lllllll}
\hline Learning Styles & Chinese & English & Law and Politic & Medicine & Business Management & PE \\
\hline Visual & 16.77 & 15.23 & 15.90 & 16.48 & 15.45 & 16.85 \\
Auditory & 14.94 & 14.00 & 14.85 & 13.76 & 15.25 & 14.90 \\
Hand-on & 16.81 & 16.40 & 17.50 & 16.55 & 17.24 & 17.55 \\
dependent & 15.48 & 16.00 & 13.00 & 15.90 & 15.16 & 15.23 \\
Independent & 17.23 & 17.75 & 18.02 & 18.05 & 18.20 & 16.65 \\
Group-oriented & 14.77 & 15.73 & 15.65 & 13.35 & 14.44 & 17.55 \\
Individual-oriented & 17.81 & 18.50 & 18.55 & 18.24 & 17.55 & 17.88 \\
Analytical & 15.71 & 14.23 & 14.18 & 14.88 & 13.50 & 14.12 \\
Holistic & 13.29 & 14.97 & 16.85 & 14.84 & 14.65 & 15.05 \\
Random & 16.50 & 15.33 & 14.15 & 14.92 & 15.50 & 15.50 \\
Serialist & 15.74 & 15.53 & 15.10 & 15.65 & 16.52 & 14.50 \\
Impulsive & 13.35 & 15.65 & 13.63 & 14.60 & 14.52 & 17.70 \\
Reflective & 18.74 & 17.65 & 18.30 & 18.03 & 17.32 & \\
\hline
\end{tabular}

A one-way ANOVA was carried out to determine whether the learning styles preferences of Tujia students vary significantly with their majors. (See Table 3) The results indicated that differences of learning style preferences in terms of different majors were significant for some learning style variables. For random style ( $F=4.750, p=0.000)$, it could be said safely that the differences of random style were extremely significant among the six majors. The dependent style was very significant among the six majors $(\mathrm{F}=4.416, \mathrm{p}=0.002)$. For the analytical style $(\mathrm{F}=3.241, \mathrm{p}=0.007)$ and holistic style $(\mathrm{F}=4.235, \mathrm{p}=0.001)$, similar claims could be made. A Post-Hoc Test was carried out to compare the differences of the learning styles between every two departments, to find out where the significant differences happen and to verify the observational results. 
TABLE 3

ONE-WAY ANOVA FOR LEARNING STYLES DIFFERENCES AMONG SIX MAJORS

\begin{tabular}{|c|c|c|c|c|c|c|}
\hline & & Sum of Squares & df & Mean square & F & Sig \\
\hline \multirow[t]{3}{*}{ Visual } & Between Groups & 60.695 & 5 & 12.139 & 1.276 & .278 \\
\hline & Within Groups & 1332.326 & 140 & 9.517 & & \\
\hline & Total & 1393.021 & 145 & & & \\
\hline \multirow{3}{*}{ Auditory. } & Between Groups & 43.284 & 5 & 8.657 & .971 & .438 \\
\hline & Within Groups & 1248.531 & 140 & 8.918 & & \\
\hline & Total & 1291.815 & 145 & & & \\
\hline \multirow{3}{*}{ Hand-on } & Between Groups & 33.365 & 5 & 6.673 & .652 & .661 \\
\hline & Within Groups & 1433.292 & 140 & 10.238 & & \\
\hline & Total & 1466.658 & 145 & & & \\
\hline \multirow[t]{3}{*}{ Independent } & t Between Groups & 41.683 & 5 & 8.337 & .767 & .575 \\
\hline & Within Groups & 1522.536 & 140 & 10.875 & & \\
\hline & Total & 1564.219 & 145 & & & \\
\hline \multirow{3}{*}{ Dependent } & Between Groups & 236.103 & 5 & 47.221 & 4.416 & $.002 *$ \\
\hline & Within Groups & 1594.582 & 140 & 11.930 & & \\
\hline & Total & 1830.685 & 145 & & & \\
\hline \multirow[t]{3}{*}{ Group } & Between Groups & 135.518 & 5 & 27.104 & 1.816 & .113 \\
\hline & Within Groups & 2089.496 & 140 & 14.925 & & \\
\hline & Total & 2225.014 & 145 & & & \\
\hline \multirow[t]{3}{*}{ Individual } & Between Groups & 27.230 & 5 & 5.446 & .609 & .693 \\
\hline & Within Groups & 1251.599 & 140 & 8.940 & & \\
\hline & Total & 1278.829 & 145 & & & \\
\hline \multirow[t]{3}{*}{ Analytical } & Between Groups & 72.724 & 5 & 14.545 & 3.241 & $.007^{*}$ \\
\hline & Within Groups & 1287.694 & 140 & 9.91 & & \\
\hline & Total & 1360.418 & 145 & & & \\
\hline \multirow{3}{*}{ Serialist } & Between Groups & 186.705 & 5 & 37.341 & 3.214 & .129 \\
\hline & Within Groups & 1626.774 & 140 & 11.620 & & \\
\hline & Total & 1813.479 & 145 & & & \\
\hline \multirow[t]{3}{*}{ Random } & Between Groups & 120.268 & 5 & 24.054 & 4.750 & $.000^{*}$ \\
\hline & Within Groups & 708.992 & 140 & 5.064 & & \\
\hline & Total & 829.260 & 145 & & & \\
\hline \multirow[t]{3}{*}{ Impulsive } & Between Groups & 80.156 & 5 & 16.031 & 1.848 & .107 \\
\hline & Within Groups & 1214.453 & 140 & 8.675 & & \\
\hline & Total & 1294.610 & 145 & & & \\
\hline \multirow[t]{3}{*}{ Holistic } & Between Groups & 156.054 & 5 & 31.211 & 4.325 & $.001 *$ \\
\hline & Within Groups & 1010.364 & 140 & 7.217 & & \\
\hline & Total & 1166.418 & 145 & & & \\
\hline \multirow[t]{3}{*}{ Reflective } & Between Groups & 21.629 & 5 & 4.326 & .378 & .863 \\
\hline & Within Groups & 1602.981 & 140 & 11.450 & & \\
\hline & Total & 1624.610 & 145 & & & \\
\hline
\end{tabular}

$* \mathrm{p}<.05$ statistically meaningful

The results of the Post-Hoc Test did show that the major differences in four learning styles: They are dependent, analytical, holistic, and random just as observed earlier. For dependent style, the most significant difference $(\mathrm{p}=0.002)$ between English department and Law and Politics, followed by PE and Law \& Political ( $\mathrm{p}=0.0037)$, Chinese and Law and Political ( $\mathrm{p}=0.008)$, Medicine and Law and Political $(\mathrm{p}=0.008)$. As to analytical style, significant difference was found between Chinese Department and Law \& Political $(\mathrm{p}=0.003)$. For random style, significant differences were found between Chinese and English $(\mathrm{p}=0.021)$, Chinese and Management $(\mathrm{p}=0.002)$ and Chinese and Medicine $(\mathrm{p}=0.009)$.

On the whole, only four learning style preferences out of the 13 are significantly different among six majors:

The results showed that Tujia students from Law and Political Department preferred independent and holistic styles more than students from other departments and the random style was selected as negligible style only by them. This result may be related to the courses they take. As future lawyers and politicians, they should learn to work logically and independently. In this sense, it can be said the courses and training influence the learning style preferences. The finding also can be further proved by the students from Chinese Department who preferred analytical style more than those from other departments. Students from Chinese Department spend most of their time on Chinese language and literature. They have to analyze every single word when they are trying to appreciate the literary masterpieces, especially some poems from ancient times. Therefore, they are used to learning English analytically.

The results also indicated that students from Chinese Department were more oriented to random style than students from other departments, so the author tries to explain the finding in a possible way: Chinese Department is well-developed institute in Jishou University. Compared to the other departments, Chinese Department possesses more learning resources such as the relevant books or materials. Students can obtain a wider perspective by processing a large number of materials. Therefore, students from Chinese Department appreciate random style more.

Impulsive style was selected as a negligible style by all Tujia students, except those of English Department who regarded it as a minor learning style. This is an interesting finding and worth our attention though it is not statistically significant difference $(\mathrm{F}=1.848, \mathrm{p}=0.107)$. The processes of learning in Tujia area have been greatly influenced by the traditional Chinese culture and Tujia culture. Their learning style is reflective. But the situation is a little different for English major. In addition to the features of English courses and learning, they absorb in the western culture. This makes them more open-minded and eager to express themselves than students from other departments. 


\section{IMPLICATIONS FOR INSTRUCTION}

All the information generated about learning styles will be of little use to us as ESL instructors unless we can somehow apply it to the classroom and our way of teaching (Reid, 2002). The goals of this section are to examine some fundamental components of Tujia students' learning styles, then make practical suggestions for improving teaching effectiveness and trying to change the present embarrassing situation of English teaching in Jishou University.

\section{A. Establishing a Harmonious Relationship between Teachers and Tujia Students}

Teachers-students relationship plays an important role in maximizing teaching and learning effectiveness. (Chen \& Liu, 2005). For effective matching of learning and teaching styles in English classroom, teachers and students should work jointly to build up the cooperation. However, because of the different cultures and languages, most teachers and students have no communication either in class or after class.

It is vital for teachers and students to build up the cooperation. With such a harmonious atmosphere, teachers and students can know each other well including their learning styles. According to the educational psychology, learners will feel less anxiety in classroom when they have a good relationship with their teachers. In this way, they can study efficiently. If teachers expect Tujia students to get involved in learning, they should make their relationship with Tujia students more open and more relaxed.

On the one hand, teachers should win trust from the Tujia students. The harmonious relationship must be established on mutual trust. They have to understand Tujia culture, especially the different culture from Han. They should respect the Tujia customs when they are talking with Tujia students in daily life or in the classroom teaching. For example, teachers can learn a little Tujia dialects such as greetings and compliments.

On the other hand, teachers should create a friendly and supportive classroom. They should treat Tujia students as their friends, instead of acting like an authority. They should allow Tujia students to ask for some relevant information when some teachers come from developed regions of China.

\section{B. Developing the Awareness of the LS in Tujia EFL Learners}

Although it is important that instructors in Tujia locations have a clear understanding of LS, it is also important for them to realize their own LS and to know the learning strategies. A Knowledge of one's own learning style is fundamental in "learning to learn" (Kinsella,1994). Students with Tujia background will fail to gain successful language acquisition strategies, study methods without a full knowledge of LS. Most Tujia students will keep using improper learning methods, with no awareness of their own LS and their owe academic backgrounds. If teachers are willing to offer some suggestions of learning preferences, and then provide constructive feedback about the characteristic advantages and drawbacks, it is definitely to help Tujia students develop a more versatile approach to learning, not just in the EFL classroom but also in every subject across the curriculum and in many situations beyond school ( Liufeng, 2012).

\section{Administering Learning Style Assessment}

Teachers must have means of helping Tujia students identify their learning preferences before the concept of learning style accommodation and development is going to have practical value for the EFL classroom. There are some assessment instruments and activities specially designed for L2 learners to understand their own learning styles such as the "activity worksheets" in Willing's (1989) Teaching How to Learn. Inventories such as Kinsella's (1993) Perceptual Learning Strengths Survey, Reid's (1984) Perceptual Learning style Preference Questionnaire and Rebecca L. Oxford(1993) Style Analysis Survey (SAS) or the instrument used in this study can additionally aid EFL students in identifying their learning strengths and sources of academic frustration.

Before the survey is administered, to prevent students from worrying about being labeled or having the "wrong" learning style, the teachers should stress the fact that no style is better than another, and that honesty in responding will produce more accurate and practical information about each learner's special characteristics. The instructors should spend adequate time going over the guidelines for the assessment instrument, then have the students complete each item or question one at a time as a unified class, clarifying any confusing items. By doing so can students be willingly involved into the assessment and more reliable questionnaires may be received.

The next step is for the teacher to organize a whole-class discussion of the results of style assessment. Students can easily tabulate their own results and enjoy the immediate gratification by using an inventory such as the Kinsella's Perceptual Learning Preferences Survey (1993). Then the students can compare similarities and differences in general findings or on specific items. The teacher also can organize a classroom activity of learning style discussion. For example, the teacher can write the different learning styles on the blackboard and ask students to choose the learning styles that they preferred. Seeing the great variety of learning styles in one class, students know some classmates also share similar instructional likes and dislikes as well as learning strengths and difficulties.

Furthermore, the teacher should tell students not to present learning styles in term of "good or bad", but in terms of its effectiveness in a particular context. Students who lack of confidence in their ability to learn in class may become more involved when the teacher emphasizes the attributes of all learning styles. They may also feel more connected to the classroom community and less solitary in their learning struggles when they find out that fellow classmates share challenges and frustrations in university. 
Last but not least, teachers and students should use these instruments with caution. Teachers should explain to Tujia students that no instrument is perfect, that students and styles grow and change, and that the information got about learning styles must be used in the whole context of learning.

Developing Self-awareness of the Learning styles by Keeping Diaries

Considering that most of the Tujia students are individual-oriented, keeping diaries is an important way for them to understand their own learning styles. Something going on inside their minds can be reflected by keeping diaries. But this kind of diary is different from what they wrote before. Teachers should provide some guidelines about how to write and what to write. For example, students are asked to write how to deal with the problems they meet in English learning and what are their plans for learning English. The conclusions should be made every week based on their diaries.

\section{Implications for Gender-related Differences in EFL Classroom}

Based on the present study, only two significant differences of learning styles occurred among Tujia female students and male students: 1) the Tujia female students preferred visual style while Tujia male students preferred a little more on auditory style; 2) the Tujia female students were more individual-oriented than males. How should teachers react to these gender-related differences in EFL classroom?

Baumeister (1988:1094) pointed out "We can totally ignore observed gender differences, reporting any of these differences might perpetuate and legitimize them, thus continuing the unequal social treatment of women and men". Chipman (1988:47) claimed "We can downplay gender differences while reporting them, because many of these differences---though statistically significant---are small” However, if these differences are ignored, it will prevent us from understanding what is going on in front of us. These responses need to be rejected.

Teachers should look at gender differences from multiple angles and in greater depth. For examples, teachers should look not just at differences in overall means for males and females, but also at gender differences in the degree of variability within each group. Then gender-related differences should also be highlighted in the discussion (Oxford 1990a:45) For example, teachers and students, especially for Tujia female students should feel free to discuss these differences openly, bringing up any biological influences that might have helped create any contrasts between females and males such as the differences of visual and auditory styles. In addition, it is useful for teachers to emphasize what useful skills and attitudes that people of different styles can learn from each other, both across and within gender boundaries. Teachers should also improve their teaching methods to meet the needs of females and males in the classroom. In Tujia EFL classroom, female students and male students both are independent learners, so they should be treated equally. Teachers might also try using an imposed "wait time" that requires conversation dominating male students to reflect before responding; offering speeded games that giving female students lot of opportunities to speak.

The results of this study also can help teachers prepare a language learning environment that accommodates females and males alike. The classroom can be established as inclusive, welcoming everyone. Lively bulletin boards, some attractive ethnic cultural handiworks or wall decorations can send positive messages to all Tujia students.

\section{Expanding Students Learning Styles}

Using teaching strategies that are compatible with students' learning styles should not be the only approach to classroom instruction. Students need to build on the learning styles and strategies that they currently use and to expand new methods, especially for Tujia students, they need to learn how to compensate for the weaknesses of their styles and strategies in order to broaden the scope of their approaches to learning. As students grow older, in terms of academic achievement, those with mixed learning styles have a better chance of success than those with a single learning style because they can process information in different ways.

Unfortunately, in Tujia EFL classroom, even if the teachers could identify and remember each student's learning styles, they label students by their learning preferences and teach only to those preferences. While all students should have the chance to learn through their own learning styles, they also need to be open to the idea of "style flex" ---that is, students should be encouraged to diversify their style preferences (Friedman \& Alley, 1984). Similarly, teachers must assess their own teaching styles and work toward "flexing" these styles.

For Tujia students, they are all reflective learners, therefore, they can be asked to speak more and fast. Individual-oriented is also their major learning style. They prefer to work on their own, study by themselves. The individual-oriented students can be persuaded to expand their strategies by role-playing familiar situation in order to develop their conversational and social skills. Hand-on learners can be encouraged to close their eyes, sit quietly, and visually imagine words or situations. Some visual learners who need to see new words written on the blackboard should be encouraged to pronounce and use the word before seeing them. At last, because most Tujia students regarded analytical style as a negligible style, teachers should encourage them to analyze the phrases and sentences in order to improve accuracy.

As levels of student language proficiency improve, changes in learning style preferences might be evidenced and should be accompanied by changes in strategy training (Reid, 1995). For example, as Tujia students become more proficient in using the written word, visual strategies might be introduced more frequently. As hand-on students develop more visual skills, increased training in visual strategies may expand their learning repertoire. In this way, the style-strategy relationship become a dynamic one and should be welcomed in the Tujia ESL classroom. 


\section{E. Taking Advantage of Computer Assisted Instruction (CAI)}

In the reality of the classroom, it is impossible for teachers to take all of the students' learning style preferences into consideration all the time. Also, it is impossible to constantly remember how each student learns best. The CAI can be a good assistant. The CAI with a variety of learning modalities can meet the needs of different students and teachers can use CAI to enrich or supplement the basic instruction.

However, it is difficult to put the CAI into use in Tujia-Miao Autonomous Prefecture of Xiangxi because of a large amount of financial support is needed and the use of CAI requires teachers and students reach higher levels of the computer operation. But teachers can also make good use of limited network resource such as recommending useful English learning resources on the internet and communicating with students by e-mails.

\section{F. Creating a "Student-Centered" EFL Classroom}

In Jishou University, the conception of "student-centered" is widely promoted. Unfortunately, the results of interviews indicated that the "student-centered" classroom is not well-organized. What does "student-centered" mean? A "student-centered" classroom means more than allowing students to work in teams, to select their own reading and writing topics, or to participate regularly in lively class discussions. It also entails more than a "student-centered curriculum" with units reflecting the students' interests. Teachers who create a truly "student-centered" classroom understand and respect the diversity of learning style preferences within group and offer choices in how information and skills will be acquired. Reid (2002) pointed out that "A genuinely "student-centered" classroom is an educational environment that enables students to equitably develop their individual learning styles to meet the diverse demands of school and life with increased confidence and competence."

According to the results of the interviews, it can be concluded that most teachers and Tujia students know little about learning styles. They do not realize the importance of learning style preferences. Even the teachers' misconceptions of learning styles, they believe the only way to improve English proficiency of Tujia students is hard working, instead of matching teaching styles to learning style preferences. As a result, some teachers will never pay enough attention to their instructions and their students; this may be one of the reasons for the low efficiency of Tujia EFL teaching and learning.

Based on the qualitative study and quantitative study, the author offered some suggestions for instruction in Tujia EFL classroom: 1. Establishing a harmonious relationship between teachers and Tujia students. 2. Developing self-awareness of the learning styles. 3. Linking learning styles and learning strategies in the EFL classroom. 4. Expanding students' learning styles. 5. Implications for gender-related differences in EFL classroom. 6. Taking advantage of Computer Assisted Instruction (CAI). 7. Creating a "student-centered" EFL classroom.

\section{REFERENCES}

[1] Gregorc, A.F. (1979). Learning/teaching styles: Potent forces behind them. Educational Leadership, 36, $236-238$.

[2] Keefe, J.W. (1979). Leaning style: An overview. In J. W. Keefe (ed.), Student learning styles: Diagosing and prescribing programs. Reston, VA: National Association of Second School Principals.

[3] Kolb, D.A. (1984b). Experiential Learning: Experience as the source of learning and development. Englewood Cliffs, NJ: Prentice-Hall.

[4] Liu Ruiqing \& Dai Manchun. (2001). Report on the Learning Styles of EFL Learners in China. Beijing: Foreign Language Teaching and Research Press

[5] Liu, Feng. (2012). A Probe into the EFL Learning Style Preferences of Minority College Students: An Empirical Study of Tujia EFL Learners in Jishou University. Theory and Practice in Language Studies, 8, 172-177.

[6] McCarthy, B. (1980). The 4MAT system: Teaching to learning styles with right/left mode techniques. Barrington, IL: EXCEL.

[7] Oxford, R.L. (1990). Language learning strategies and beyond: A look at strategies in the context of styles. In S.S. Magan (Ed.), Shifting the instructional focus to the learner. Middlebury, VT: Northeast Conference on the Teaching of Foreign Languages.

[8] Oxford, R.L., Lavine, R.Z., \& Crookall, D. (1989). Language learning strategies, the communicative approach, and their classroom implications. Foreign language Annals, 22,(1): 29-39.

[9] Reid. J (2002). Learning styles in the ESL/EFL Classroom. Beijing: Foreign Language Teaching and Research Press.

[10] Scarcella, R. (1990). Teaching language minority students in the multicultural classroom. Englewood Cliffs, NJ: Prentice-Hall/Regents.

[11] Schmeck, R. R. (1983). Learning styles of college students: Individual differences in Cognition . New York: Academic Press.

Feng Liu, (Tujia Zu) 31, is a lecturer teaching English language in English department of Sichuan Agricultural University. He attained his MA degree of Foreign Language and Literature in Southwest Jiaotong University in China. He has interests in foreign language education and second language acquisition.

Lin Hu, 22 , is an undergraduate in English Department of Sichuan Agricultural University, China.

Junjian Gan, 22, is an undergraduate in English Department of Sichuan Agricultural University, China. 